\title{
Structures of Clusters Surrounding Ions Stabilized by Hydrogen, Halogen, Chalcogen, and Pnicogen Bonds
}

\author{
Steve Scheiner*1, Mariusz Michalczyk ${ }^{2}$ and Wiktor Zierkiewicz,*2 \\ ${ }^{1}$ Department of Chemistry and Biochemistry, Utah State University Logan, Utah 84322-0300, \\ United States \\ ${ }^{2}$ Faculty of Chemistry, Wrocław University of Science and Technology, Wybrzeże \\ Wyspiańskiego 27, 50-370 Wrocław, Poland
}

\begin{abstract}
Four $\mathrm{H}$-binding $\mathrm{HCl}$ and $\mathrm{HF}$ molecules position themselves at the vertices of a tetrahedron when surrounding a central $\mathrm{Cl}^{-}$. Halogen bonding $\mathrm{BrF}$ and $\mathrm{ClF}$ form a slightly distorted tetrahedron, a tendency that is amplified for $\mathrm{ClCN}$ which forms a trigonal pyramid. Chalcogen bonding $\mathrm{SF}_{2}$, $\mathrm{SeF}_{2}$, SeFMe, and SeCSe occupy one hemisphere of the central ion, leaving the other hemisphere empty. This pattern is repeated for pnicogen bonding $\mathrm{PF}_{3}, \mathrm{SeF}_{3}$ and AsCF. The clustering of solvent molecules on one side of the $\mathrm{Cl}^{-}$is attributed to weak attractive interactions between them, including chalcogen, pnicogen, halogen, and hydrogen bonds. Binding energies of four solvent molecules around a central $\mathrm{Na}^{+}$are considerably reduced relative to chloride, and the geometries are different, with no empty hemisphere. The driving force maximizes the number of electronegative ( $\mathrm{F}$ or $\mathrm{O}$ ) atoms close to the $\mathrm{Na}^{+}$, and the presence of noncovalent bonds between solvent molecules.
\end{abstract}

Keywords: tetrahedral; QTAIM; NBO; $\mathrm{Cl}^{-} ; \mathrm{Na}^{+}$

*Correspondence to: steve.scheiner@usu.edu, wiktor.zierkiewicz@pwr.edu.pl 


\section{INTRODUCTION}

The hydrogen bond (HB) is arguably the most important and intensively studied of all noncovalent interactions [1-4]. Besides its major role in the structure and function of countless biomolecular systems, it is intimately involved in solvation phenomena, particularly in aqueous media. In order to gain insights into the complicated aspects of solvation by H-bonding solvents, there have been numerous studies of small clusters of a single moiety surrounded by a few such molecules [5-8]. This work has yielded information concerning the preferred geometries of such clusters, details about the forces holding them together, and their flexibility in terms of the energetic cost of deviating from an optimal structure.

The replacement of the bridging proton of a $\mathrm{HB}$ with one of several electronegative atoms leads to the concept of parallel noncovalent interactions. Perhaps the first such noncovalent bond to be recognized [9-16] was the halogen bond (XB). Halogen bonds represent a potentially powerful force that can, for example, stabilize the $\beta$-hairpin structure [17] of a protein system, in the same way as the more traditional HBs. Halogen bonding has become widely accepted as a means of anion recognition, as well as templated self-assembly and even organocatalysis [18]. Just as the elements of the halogen family $(\mathrm{Cl}, \mathrm{Br}$, I, etc) can replace $\mathrm{H}$ as a bridging atom in strongly bound complexes, the same is equally true for other columns of the periodic table. In particular, the S,Se, etc group can engage in chalcogen bonds (YBs) [19-25], and the same is true of the P,As family which forms pnicogen bonds (ZBs) [26-34].

Given the parallel nature of these latter noncovalent bonds and the more thoroughly studied $\mathrm{HB}$, one would like to understand whether the clustering of such molecules around a central moiety obeys the same patterns as do the analogous H-bonded clusters. This question is of growing importance as it is becoming increasingly apparent that chalcogen bonds are involved in solution [35] or for supramolecular capsules [36] to give two simple examples. Halogen bonds, too, play out in this arena as they are involved in biomimetic processes [37] and have unique properties in supramolecular chemistry [38].

There has been relatively little study of this question to date. Most of the earlier work concerns the clustering of molecules around each other, without a central species. For example, pnicogen bonding accounts for the structures of $\left(\mathrm{PH}_{2} \mathrm{~F}\right)_{n}$ and $\left(\mathrm{PH}_{2} \mathrm{Cl}\right)_{n}$ clusters [39] and aggregates [40] of $\mathrm{NH}_{3}, \mathrm{PH}_{3}$, and $\mathrm{PFH}_{2}$. Similarly, halogen bonds in four-membered mixed clusters of $\mathrm{HF}$ and $\mathrm{FCl}$ [41] form ring structures that appropriately mix $\mathrm{HBs}$ with XBs. A 
theoretical study [42] examined intermolecular halogen bond properties in one-dimensional NCX clusters as large as 10 monomers $(\mathrm{X}=\mathrm{Cl}$ and $\mathrm{Br})$ and noted cooperative effects. With regard to placement of a central molecule within a cluster, the halogen bonds that stabilize $\mathrm{Cl}_{2}$ and $\mathrm{Br}_{2}$ within cages of water molecules [43] have been examined. The interactions of a halide ion with neutral molecules via HBs, XBs, or related noncovalent bonds has seen some prior scrutiny [44]. There is also a burgeoning effort [45-57] to design molecules that bind to halides and other anions via XBs, YBs, ZBs, and even tetrel bonds (Si,Ge family) via a sort of clustering in that the anion is held jointly by several such bonds.

However, there is little known at present about how a small number of $\mathrm{XB}, \mathrm{YB}$, or ZB molecules might arrange themselves around a central species, and how their geometries might differ from analogous H-bonding molecules. Might the molecules dispose themselves as far as possible so as to minimize repulsive steric or electrostatic interactions, or might they be drawn together via intermolecular attractions? How flexible would this optimal arrangement be; how much energy would be required for deformations of various sorts? Does the optimal arrangement depend upon the strength of the noncovalent bond to the central species? Do halogen bonding molecules differ from chalcogen or pnicogen bonds in these respects, as well as any comparison with HBs. The present communication attempts to answer these questions via quantum calculations.

\section{SYSTEMS AND COMPUTATIONAL METHODS}

$\mathrm{Cl}^{-}$and $\mathrm{Na}^{+}$were chosen as monatomic central ions, whose simplicity rules out secondary interactions, and permits elucidation of the rules governing solvation of ions of both positive and negative charge. With regard to surrounding molecules, $\mathrm{HCl}, \mathrm{HF}$ and $\mathrm{HOH}$ were taken as examples of H-bonding systems. Halogen-bonding molecules were all linear in character: $\mathrm{BrF}$, $\mathrm{ClF}$ and $\mathrm{ClC} \equiv \mathrm{N}$. Molecules that engage in chalcogen bonds sampled here are $\mathrm{SF}_{2}, \mathrm{SeF}_{2}$, $\mathrm{SeFCH}_{3}$, and $\mathrm{Se}=\mathrm{C}=\mathrm{Se}$, the last of which is a linear molecule. Corresponding pnicogen bonding molecules were $\mathrm{PF}_{3}, \mathrm{AsF}_{3}$, and $\mathrm{As} \equiv \mathrm{CF}$. H-bonding is abbreviated as $\mathrm{HB}$, with $\mathrm{XB}, \mathrm{YB}$, and $\mathrm{ZB}$ used to refer to halogen, chalcogen, and pnicogen bonding, respectively. Surrounding molecules are referred to here as solvent for ease of explanation.

Each of the two central ions was surrounded by a number of these solvent molecules, up to 4 , and the geometries optimized by the M06-2X method in conjunction with the aug-cc-pVDZ 
basis set [58,59]. This DFT functional and basis set have had past success $[47,60-76]$ in studying systems of these sorts.

The interaction energies of the complexes were calculated as the electronic energy difference between the complex and its constituent parts, then corrected for basis set superposition error (BSSE) [77]. All computations were carried out with Gaussian 09 [78]. For the isolated molecules molecular electrostatic potentials (MEPs) were calculated on the 0.001 au electron density isosurface, and the extrema were computed using the WFA-SAS program [79]. The QTAIM analysis was applied in order to characterize the intermolecular interactions in the complexes discussed in this work [80], and supplemented by NBO results [81-83]. The nature of minima were verified by the absence of negative frequencies. However, as described below, due to the extraordinary flatness of some of the potential energy surfaces, it was not possible to locate geometries with all positive vibrational frequencies in every case. However, the energy of each of these points is static with respect to further geometry fluctuations, and any negative frequencies are very small ones.

\section{RESULTS}

\section{Clustering around $\mathrm{Cl}^{-}$}

In the case of two solvating molecules, neither HBs nor YBs lead to linear structures, with the two solvent molecules poised opposite one another. The two $\mathrm{HCl}$ molecules are situated some $109^{\circ}$ from one another when surrounding the $\mathrm{Cl}^{-}$anion, as illustrated in Fig 1a. The same arrangement is observed when the $\mathrm{H}$-bonding $\mathrm{HCl}$ is changed to $\mathrm{FSeMe}$ which engages in a chalcogen bond with the $\mathrm{Cl}^{-}$anion and with the same angle separating the two Se atoms (Fig 1b). Interestingly, there is a second minimum for this complex as well, albeit higher in energy by some $1.61 \mathrm{kcal} / \mathrm{mol}$, shown in Fig 1c The $\theta(\mathrm{SeClSe})$ angle is a bit more acute in the secondary minimum, only $90^{\circ}$. The angle opens up to $132^{\circ}$ when the chalcogen bonding molecule is changed to the linear $\mathrm{Se}=\mathrm{C}=\mathrm{Se}$ molecule, as illustrated in Fig 1d. Note also that the $\mathrm{R}(\mathrm{Cl} \cdot \mathrm{Se})$ distances are quite a bit longer in the latter case.

The tetrahedral angles remain in place when a third $\mathrm{HCl}$ molecule is added to the solvation sphere, along with a bit of stretching of the H-bond lengths relative to the two-molecule shell as is apparent in Fig 2a. There is a good deal less symmetry in the SeCSe chalcogen-bonding trimer in Fig $2 \mathrm{~b}$. Two of the $\theta(\mathrm{SeClSe})$ angles are quite acute at $77^{\circ}$ but the third such angle opens up to $126^{\circ}$. The sum of these three angles is $280^{\circ}$, much smaller than the $329^{\circ}$ sum for the 
$\mathrm{Cl}^{-}(\mathrm{HCl})_{3}$ system, suggesting a more pyramidal, i.e. less flat structure, with the three SeCSe units closer together than are the $\mathrm{HCl}$ molecules. In other words, there is seen even in the trisolvated systems the beginnings of a trend for YB molecules to cluster together.

In the case of $n=4$, one can see a ramping up of the differences between $\mathrm{HB}$ and $\mathrm{XB}$ or YB clustering. The $\mathrm{H}$-bonding $\mathrm{HCl}$ molecules in Fig 3a maintain their tetrahedral arrangement in the presence of a fourth $\mathrm{HCl}$ as well, with all $\theta(\mathrm{HClH})$ angles equal to $109^{\circ}$. As indicated in the first row of Table 1, this complex is bound together with a total interaction energy of 66.0 $\mathrm{kcal} / \mathrm{mol}$. The HF molecules are similarly arranged tetrahedrally in Fig 3b, with a small increase in the interaction energy to $74.5 \mathrm{kcal} / \mathrm{mol}$.

The change from HBs to XBs begins to introduce small deviations from this tetrahedral structure. The placement of four BrF molecules around the chloride lead to the structure in Fig $3 \mathrm{c}$ which remains close to tetrahedral, although two of the $\theta(\mathrm{BrClBr})$ angles are as large as $115^{\circ}$. This $\mathrm{Cl}^{-}(\mathrm{BrF})_{4}$ complex is held together by an interaction energy of $92.6 \mathrm{kcal} / \mathrm{mol}$, indicative of the strong halogen bonding. Forcing this geometry into a strictly tetrahedral one with all four $\theta(\mathrm{BrClBr})$ angles equal to $109.5^{\circ}$ does not raise the energy by any meaningful amount. As seen in the last column of Table 1 , this deformation costs only $0.2 \mathrm{kcal} / \mathrm{mol}$. The deviation from tetrahedral angles progresses further for the halogen-bonding $\mathrm{ClF}$ molecules in Fig $3 \mathrm{~d}$ where the six $\theta(\mathrm{ClClCl})$ angles span a $20^{\circ}$ range between $98^{\circ}$ and $118^{\circ}$. Nonetheless, forcing this complex into a pure tetrahedral structure does not require significant energy. In the case of $\mathrm{ClCN}$ molecules, the structure has shifted radically to what might best be described as a trigonal pyramid in Fig 3e. The three $\theta(\mathrm{ClClCl})$ angles that include the apex of the pyramid are all less than $90^{\circ}$. However, this structure is not the only minimum on the surface; another that is only $0.3 \mathrm{kcal} / \mathrm{mol}$ higher is slightly closer to a tetrahedral structure. Or rather Fig $3 \mathrm{f}$ might be better described as a trigonal pyramid but distorted in a way that is opposite to the flattening in Fig 3e: the topmost molecule makes a $\theta(\mathrm{ClClCl})$ angle with the three other $\mathrm{ClCN}$ molecules of 126$135^{\circ}$, whereas the three bottom molecules are all within $83^{\circ}$ of one another. The potential surface for moving these solvent molecules around is quite flat. Forcing the system into a tetrahedral geometry requires less than $0.4 \mathrm{kcal} / \mathrm{mol}$. In summary, the tetracoordinated systems are highly tetrahedral for HBs. They deviate from this structure a bit for some of the halogenbonded systems, but forcing them into a tetrahedral structure is quite facile. 
The chalcogen-bonded complexes tend to deviate more from tetragonality. The optimized geometry of $\mathrm{Cl}^{-}\left(\mathrm{SF}_{2}\right)_{4}$ in Fig $4 \mathrm{a}$ is exemplary of these structures. These complexes can be loosely described as distorted trigonal pyramids. The $\mathrm{S}$ atom at the apex of this pyramid makes small angles of less than $100^{\circ}$ with the three $\mathrm{S}$ atoms in the base. But the latter are not evenly spaced into an equilateral triangle by any means, with $\theta(\mathrm{SClS})$ angles varying from 55 to $167^{\circ}$. The general characteristics remain in place when the $S$ atom is replaced by Se, as in Fig $4 b$. The three $\theta(\mathrm{SeClSe})$ angles involving the apical Se are again small, $72-102^{\circ}$, and the three angles involving the Se atoms in the pyramid base are quite varied, from $73^{\circ}$ to $161^{\circ}$. The general theme continues if one of the $\mathrm{F}$ atoms of each $\mathrm{SeF}_{2}$ molecule is replaced by a methyl group, as in Fig $4 \mathrm{c}$. The apical angles lie in the $81^{\circ}-105^{\circ}$ range, and one again sees variation in the angles within the base: $87^{\circ}-122^{\circ}$.

There is some question as to the cause of the clustering of the solvent molecules in such a way as to free up space in one hemisphere of the $\mathrm{Cl}^{-}$. Might this be caused by attractive interactions between the solvent units? In order to address this issue, linear SeCSe molecules were considered which do not have substituents that approach the other solvent molecules. As is evident in Fig 4d, even these linear molecules adopt this sort of open umbrella structure. The three $\theta(\mathrm{SeClSe})$ angles involving the umbrella handle are all about $74^{\circ}$; those between the three spokes are quite variable, ranging from $75^{\circ}$ to $140^{\circ}$. The $\mathrm{Cl}^{-}(\mathrm{SeCSe})_{4}$ complexes are the most weakly bound of the chalcogen bonded systems, with a total interaction energy of $47 \mathrm{kcal} / \mathrm{mol}$, as compared to $90 \mathrm{kcal} / \mathrm{mol}$ for the $\mathrm{SeF}_{2}$ complexes. The chalcogen-bonded systems are also clearly energetically separable from tetrahedral structures. As noted by the last column of Table 1, deformation of the optimized geometries into tetrahedral structures costs between 2 and 8 $\mathrm{kcal} / \mathrm{mol}$.

Given the differences between halogen and chalcogen bonding, it seems incumbent to extend consideration to pnicogen bonding as well. The structures of two such complexes, with $\mathrm{PF}_{3}$ and $\mathrm{AsF}_{3}$ as solvating molecules are depicted in Figs 5a and 5b, respectively. These structures retain the open space in one hemisphere of the central chloride, characteristic of the chalcogen bonds, although they differ a bit in terms of internal angles. $\mathrm{AsF}_{3}$ might be best considered a variant of the umbrella, with the three handle-spoke angles between $84^{\circ}$ and $89^{\circ}$, although two of the spokes are quite close together with $\theta(\mathrm{AsClAs})=90^{\circ}$. The $\mathrm{PF}_{3}$ analogue is closer to a see-saw with the $\theta(\mathrm{PClP})$ angle between the two opposite $\mathrm{P}$ atoms equal to $169^{\circ}$; all 
other angles are less than $96^{\circ}$. The open hemisphere persists and opens up even more for the linear AsCF solvating molecules, as shown in Fig 5c. The three $\theta$ (AsClAs) handle-spoke angles for this structure are quite acute, between $73^{\circ}$ and $77^{\circ}$. The pnicogen-bonded systems are a bit more weakly bound than their chalcogen-bonding analogues. But they too resist deformation into a tetrahedral geometry, by amounts varying between 2 and $4 \mathrm{kcal} / \mathrm{mol}$.

One may surmise that the aggregation of solvent molecules on one side of the central anion may point to attractive interactions between them. In order to examine this possibility, QTAIM analysis of each of the optimized structures was carried out and the results presented in Table 2 . The first column displays the density at the bond critical point corresponding to the primary interaction involving the central $\mathrm{Cl}$ and the bridging atom of the solvent molecule, whether $\mathrm{H}$, halogen, chalcogen, or pnicogen. Due to the asymmetry of these complexes, this quantity spans a range over the four interactions involved. This primary $\rho_{\mathrm{BCP}}$ lies in the general range of 0.01 $0.04 \mathrm{au}$, but there is no clear relationship between this quantity and the total interaction energy in Table 1. This poor correlation may be due to a large role played by electrostatic attraction, as evidenced by a close relationship that exists between binding energy and the maximum in the electrostatic potential, $\mathrm{V}_{\mathrm{s}, \max }$, of most of the solvent molecules, a correlation which decays for the H-bonding systems.

The second column contains the electron densities for any secondary interactions identified by QTAIM, those between solvent molecules. It may first be noted that there are no such noncovalent bonds in the first five complexes, the HB and $\mathrm{XB}$ complexes which prefer a tetrahedral geometry, and in which the four solvent molecules lie furthest from one another. The YB and ZB structures, on the other hand, where the solvent molecules cluster into one hemisphere around the central $\mathrm{Cl}^{-}$, all manifest noncovalent bonds between these molecules. The $\mathrm{SF}_{2}$ system, for example, contains two $\mathrm{S} \cdot \mathrm{S}$ interactions which may be classified as chalcogen bonds, and another bond between the central $\mathrm{Cl}$ and a $\mathrm{F}$ atom. The magnitudes of these critical point densities are substantial, as large as 0.039 for one $\mathrm{S} \cdot \mathrm{S}$ interaction. A pair of $\mathrm{H} \cdot \mathrm{Cl} \mathrm{HBs}$ occur for the SeFMe complex, as well as two $\mathrm{H}^{\cdot}$ Se HBs. With respect to the linear SeCSe molecules, the total interaction energy is bolstered by four separate $\mathrm{Se} \cdot$ 'Se YBs. Similar patterns are observed for the $\mathrm{ZB}$ systems as well. Attractive interactions between $\mathrm{F}$ and $\mathrm{Z}$ atoms are present for both $\mathrm{PF}_{3}$ and $\mathrm{AsF}_{3}$ clusters. The linear AsCF solvent molecules are held together by As ${ }^{*}$ As $\mathrm{ZBs}$ as well as an interesting As ${ }^{\circ} \mathrm{C}$ attraction, which might be designated a tetrel bond. 
NBO analysis confirms the conclusions of the QTAIM data, from the perspective of interorbital charge transfers. Table 3 reports the various charge transfers that take place between solvent molecules, via their energetic measure of $\mathrm{E}(2)$. Both the $\mathrm{HB}$ and $\mathrm{XB}$ complexes in the first five rows show no such transfers, which are clearly present in the $\mathrm{YB}$ and $\mathrm{ZB}$ structures. According to NBO, the principal interactions that arise are $\mathrm{YBs}$, in the form of $\mathrm{Y}_{\mathrm{lp}} \rightarrow \sigma^{*}(\mathrm{YF})$ or $F_{1 p} \rightarrow \sigma^{*}(Y F)$, supplemented in some cases by weak HBs. Even for the linear SeCSe molecules, there is still a set of weak YBs, in this case characterized by $\sigma(\mathrm{SeC}) \rightarrow \sigma^{*}(\mathrm{SeC})$ transfers. Very similar observations apply to the ZB complexes in the last three rows, and again some of the linear AsCF noncovalent bonds appear as $\sigma(\mathrm{AsC}) \rightarrow \sigma^{*}(\mathrm{AsC})$.

One can perhaps understand the tetrahedral nature of the tetra-coordinated clusters for the linear HB and XB systems on the basis of maximal separation between solvent molecules. Neither QTAIM nor NBO suggest any sort of attractive interactions between the surrounding solvent molecules. One can provide an additional handle on such possible interactions by calculating the simple pairwise interaction between a pair of solvent molecules, in the absence of the remainder of the complex, and corrected for basis set superposition error. The pairwise interaction energies between solvent molecules in these tetrahedral arrangements are all positive, e.g. $+0.6 \mathrm{kcal} / \mathrm{mol}$ for $\mathrm{BrF}$ and $+1.4 \mathrm{kcal} / \mathrm{mol}$ for $\mathrm{HF}$. On the other end of this spectrum are systems with clear attractive forces between solvent molecules. Taking $\mathrm{Cl}^{-}\left(\mathrm{SF}_{2}\right)_{4}$ as an example of this sort of system, QTAIM and NBO suggest a number of attractive interactions between the $\mathrm{SF}_{2}$ units, mostly $\mathrm{S} \cdot \mathrm{S}$ chalcogen bonds. The pairwise interaction energies are mostly fairly small, but there is one significant negative (attractive) interaction, between two of the $\mathrm{SF}_{2}$ molecules in the base of the pyramid, which are placed only $55^{\circ}$ apart. This interaction amounts to some $-1.05 \mathrm{kcal} / \mathrm{mol}$, and tilts the balance of the total pairwise interactions slightly into the negative range.

One might anticipate similarly negligible interactions between the linear chalcogen-bonding SeCSe molecules. But the deformation energy required to transition the open hemisphere structure of Fig $4 \mathrm{~d}$ into a tetrahedral geometry is appreciable, at $1.8 \mathrm{kcal} / \mathrm{mol}$. The QTAIM analysis provides a rationale for this preference for close arrangement of solvent molecules with indications of $\mathrm{Se} \cdot$ - $\mathrm{Se}$ chalcogen bonds, with $\rho_{\mathrm{BCP}}=0.005$ au. This supposition is supported by the NBO data in Table 3, with multiple $\sigma(\mathrm{SeC}) \rightarrow \sigma^{*}(\mathrm{SeC}) \mathrm{E}(2)$ values of $0.2-0.3 \mathrm{kcal} / \mathrm{mol}$. Despite the linear nature of the $\mathrm{AsCF}$ molecule, the arrangement of four of these species around the 
chloride leads to a number of intermolecular interactions, documented in Tables 2 and 3. Most of the pairwise interaction energies are negative, leading to a cumulative total of $-2.1 \mathrm{kcal} / \mathrm{mol}$, which accounts for the substantial deformation energy required to place this complex into a tetrahedral geometry.

The $\mathrm{Cl}^{-}(\mathrm{ClC} \equiv \mathrm{N})_{4}$ complex lies in the middle between these two extremes. This system has a very flat potential energy surface, but nonetheless with a slight propensity toward an open hemisphere, with solvent molecules clustering on one side. There is some question as to the reason for this clustering, given that neither QTAIM nor NBO suggest significant attractive interactions between the $\mathrm{ClCN}$ molecules. Taking the open hemisphere geometry depicted in Fig $3 \mathrm{e}$, the pairwise energies between the various $\mathrm{ClCN}$ molecules are all slightly repulsive, with counterpoise-corrected interaction energies of $+0.4-+0.6 \mathrm{kcal} / \mathrm{mol}$. The weakness of these intermolecular forces accounts for the very small energy changes as they are moved around, from Fig $3 \mathrm{c}$ to $3 \mathrm{~d}$.

It may be noted that the values of the primary QTAIM data in Table 2 do not correlate closely with the interaction energies in Table 1 . For example, $-\mathrm{E}_{\text {int }}$ for $\mathrm{AsF}_{3}$ is equal to 77.8 $\mathrm{kcal} / \mathrm{mol}$, as compared to 70.0 for $\mathrm{SF}_{2}$. However, the primary $\rho_{\mathrm{BCP}}$ for the former system is considerably smaller than for the latter. Part of this discrepancy arises from the multiple secondary critical points, and their contribution to the total interaction. Another source of stability can be traced to the multiple NBO measures of charge transfer that are documented in Table 3. Because of the various contributions to the total interaction in these systems, their overall stability cannot be ascribed to any single measure of one particular interatomic interaction.

\section{Clustering around $\mathrm{Na}^{+}$}

Although a positively charged species will obviously not engage in $\mathrm{HB}, \mathrm{XB}, \mathrm{YB}$ or $\mathrm{ZB}$ with a Lewis acid, it is nonetheless useful to understand how the same solvent molecules might cluster around a cation. The $\mathrm{Na}^{+}$monocation was chosen as a central species, surrounded by some of the same molecules as were considered for $\mathrm{Cl}$ - solvation above. The interaction energies in these tetrasolvated clusters are displayed in Table 4. Comparison with the analogous data for the chloride anion indicate considerably weaker interactions with the cation. Binding with the HF molecules is reduced from $74.5 \mathrm{kcal} / \mathrm{mol}$ for $\mathrm{Cl}^{-}$to $59.8 \mathrm{kcal} / \mathrm{mol}$ for $\mathrm{Na}^{+}$. The interactions with 
the halogen bonding $\mathrm{BrF}$ and $\mathrm{ClF}$ are reduced to less than half, with similar deep cuts involved with the YB molecules; ZB drop also albeit by not quite as much.

The geometries of these clusters are gathered in Fig 6, where it may first be seen that the structure of the HF cluster is tetrahedral, whereas the intermolecular $\mathrm{OH} \cdot \mathrm{O} \mathrm{H}$-bonding between water molecules pulls the cluster in Fig $6 \mathrm{~b}$ into a more pyramidal geometry, with handle-spoke angles of $132-135^{\circ}$. The system alters into a square planar shape when $\mathrm{Na}$ is approached by the $\mathrm{F}$ atoms of $\mathrm{FBr}$ and $\mathrm{FCl}$. For those solvents with more than one $\mathrm{F}$ atom, at least two of the latter participate in the interactions with $\mathrm{Na}$, as is evident in the remainder of Fig 6. QTAIM analysis of these last several structures suggests there might be attractions between $\mathrm{F}$ atoms of different molecules in the form of weak F $\cdot F$ halogen bonds. The last two complexes in Figs $6 \mathrm{~g}$ and $6 \mathrm{~h}$ may benefit from intersolvent $\mathrm{Z} \cdot \mathrm{F}$ pnicogen bonds (the $\rho_{\mathrm{BCP}}$ between $\mathrm{Z}$ and $\mathrm{F}$ atoms is about $0.01 \mathrm{au}$ ). In summary, the central cation interacts with the most electronegative atom of the surrounding solvent. While this is $\mathrm{O}$ for $\mathrm{HOH}$, it is $\mathrm{F}$ for the others. It also appears that the $\mathrm{Na}^{+}$ will interact with as many $\mathrm{F}$ atoms as possible, two from each solvent molecule for $\mathrm{YF}_{2}$ and $\mathrm{ZF}_{3}$. Unlike the clustering around the chloride, the solvent molecules do not cluster together so as to leave an empty hemisphere around the $\mathrm{Na}^{+}$.

One reason for the reduced interactions with the cation are of course due to the loss of the extra binding introduced by the $\mathrm{HB}, \mathrm{XB}, \mathrm{YB}$, and $\mathrm{ZB}$ with the anion. Another reason has to do with the electrostatic potentials surrounding these solvents. These potentials are displayed in Fig 7 where the most positive and negative regions are represented by blue and red, respectively. Table 5 lists the maximum and minimum value of this potential and shows that the maximum of each is more intense than is its minimum. Taking FBr as an example, the maximum along the $\sigma$ hole of the $\mathrm{Br}$ atom is $+47 \mathrm{kcal} / \mathrm{mol}$, four times larger than the magnitude of the minimum at $11.8 \mathrm{kcal} / \mathrm{mol}$ which is situated on the $\mathrm{F}$ atom. Indeed, overall the maxima range from +43 to $+68 \mathrm{kcal} / \mathrm{mol}$, dwarfing the minimum range of -9 to $-33 \mathrm{kcal} / \mathrm{mol}$.

\section{DISCUSSION AND CONCLUSIONS}

There is some prior work that has a bearing on the results reported here. In the first place, Taylor's group [84] used a collection of experimental and theoretical approaches to consider a Te atom that is bound on both sides by $\mathrm{N}$ atoms in a 5-membered ring, and found particularly strong chalcogen bonding to anions, and a close relationship between $\Delta \mathrm{G}$ and the electrostatic potential surrounding the Te. Perhaps most importantly the data confirmed the reliability of DFT 
calculations. An earlier calculation [85] had considered mixed clusters wherein a central fluorinated methane is surrounded by $1-5 \mathrm{CO}_{2}$ units, and found a similar clustering of solvent molecules in one hemisphere of the central unit. The authors attributed this effect to a dominant attractive interaction which might be termed a $\mathrm{C} \cdot \mathrm{F}$ tetrel bond. In the context of a central cation, a set of four BrF molecules formed a cyclic ring around one of several metal ions [86] with bond paths connecting the central metal to the $\mathrm{Br}$ atoms. However, this structure is primarily stabilized by $\mathrm{Br} \cdot \mathrm{F}$ XBs between the solvent molecules. Grabowski placed [87] a $\mathrm{NH}_{4}{ }^{+}$cation at the center of $\mathrm{HCN}$ or $\mathrm{N}_{2}$ solvent molecules and found the former cluster first along $\mathrm{NH}$ bonds, leading to a tetrahedral $\mathrm{NH}_{4}{ }^{+}(\mathrm{HCN})_{4}$ shape, as observed here for $\mathrm{Na}^{+}$. The ability of SeCSe to engage in a chalcogen bond is reinforced by earlier calculations that showed that its smaller SCS cousin is a potent Lewis acid in interactions with various bases [88], including diazines [89], with a chalcogen bond that is stronger than any HB that might form. There is very recent experimental verification that a P atom can serve as electron donor in a halogen [90] or chalcogen bond [91] even in a pentavalent bonding situation [92].

With respect to the level of theory, past calculations have been performed with various means of including correlation. The particular brand of DFT applied here, M06-2X, supplies somewhat higher interaction energies than those derived from MP2, as may be seen by comparison of the second and last columns of Table 1. This difference amounts to roughly some $10 \%$ on average. The actual difference would likely be substantially smaller were all the complexes re-optimized at the MP2 level, so this discrepancy can be considered an upper limit. However, and most importantly, since this discrepancy is more or less uniform, the patterns are consistent from one method to the other.

While the surrounding molecules have been mentioned here as solvent molecules, the distinction with a true solution must be understood. The complexes analyzed here represent minima on a potential energy surface, some of them rather shallow. So the structures would best be understood in the context of gas-phase geometries at low temperature. Within the context of a solution, there would be many more solvent molecules, all of them moving very rapidly, and the structure around each ion evolving quickly over the course of a measurement.

In summary, sets of four H-bonding or halogen-bonding molecules tend to position themselves around a central anion along the vertices of a tetrahedron. This pattern changes, of course, if the solvent molecules are capable of interacting with one another, as would be the case 
with $\mathrm{HOH}$ molecules, which can engage simultaneously in HBs with each other, as well as with the central anion.

In the case of chalcogen or pnicogen bonding molecules, there is a trend for the four solvent molecules to occupy a single hemisphere around the central anion, leaving the other hemisphere largely empty. This arrangement is caused in part by weak intersolvent attractive forces, which are present even in the case of linear solvent molecules like $\mathrm{Se}=\mathrm{C}=\mathrm{Se}$ and $\mathrm{As} \equiv \mathrm{CF}$ as chalcogen and pnicogen bonding agents, respectively. These configurations are more stable than a purely tetrahedral arrangement in amounts varying between 2 and $8 \mathrm{kcal} / \mathrm{mol}$.

These same molecules position themselves differently in the presence of a cation like $\mathrm{Na}^{+}$. The electronegative F/O atom approaches the cation directly in a tetrahedral arrangement in the case of $\mathrm{HF}$, and nearly so for $\mathrm{H}_{2} \mathrm{O}$. When attached to another halogen atom, as in $\mathrm{FBr}$ or $\mathrm{FCl}$, the $\mathrm{F}$ atoms lie in a square plane, permitting the formation of intersolvent XBs. When the solvent molecule contains more than one $\mathrm{F}$, as in $\mathrm{SeF}_{2}$ or $\mathrm{AsF}_{3}$, two $\mathrm{F}$ atoms of each solvent molecule engage directly with the $\mathrm{Na}^{+}$, while also allowing intersolvent chalcogen or pnicogen bonds. The interaction energies of these tetracoordinated systems are considerably smaller for a central cation than for the anionic analogue. In no case do the solvent molecules cluster together so as to leave an empty hemisphere around the $\mathrm{Na}^{+}$.

\section{ACKNOWLEDGEMENTS}

This work was financed in part by a statutory activity subsidy from the Polish Ministry of Science and Higher Education for the Faculty of Chemistry of Wroclaw University of Science and Technology. A generous allocation of computer time from the Wroclaw Supercomputer and Networking Center is acknowledged. 


\section{REFERENCES}

[1] P. Schuster, G. Zundel, C. Sandorfy, The Hydrogen Bond. Recent Developments in Theory and Experiments. North-Holland Publishing Co., Amsterdam, 1976.

[2] S. Scheiner, Hydrogen Bonding: A Theoretical Perspective, Oxford University Press, New York, 1997.

[3] S.J. Grabowski, Hydrogen Bonding - New Insights. Springer, Dordrecht, Netherlands, 2006.

[4] G. Gilli, P. Gilli, The Nature of the Hydrogen Bond, Oxford University Press, Oxford, UK, 2009.

[5] T.V. Serebryanskaya, A.S. Novikov, P.V. Gushchin, M. Haukka, R.E. Asfin, P.M. Tolstoy, V.Y. Kukushkin, Identification and H(D)-bond energies of C-H(D) $\cdots \mathrm{Cl}$ interactions in chloride-haloalkane clusters: a combined X-ray crystallographic, spectroscopic, and theoretical study, Phys. Chem. Chem. Phys. 18 (2016) 14104-14112.

[6] R.P. Matthews, T. Welton, P.A. Hunt, Hydrogen bonding and [small pi]-[small pi] interactions in imidazolium-chloride ionic liquid clusters, Phys. Chem. Chem. Phys. 17 (2015) 14437-14453.

[7] R.B. Viana, A.B.F. da Silva, Interaction between $\mathrm{PH}_{3}$ and small water clusters: Understanding the electronic and spectroscopic properties, Comput. Theor. Chem. 1059 (2015) 35-44.

[8] S. Jahangiri, V. Legris-Falardeau, G.H. Peslherbe, Computational investigation of the hydration of alkyl diammonium cations in water clusters, Chem. Phys. Lett. 621 (2015) 85-90.

[9] K.E. Riley, C.L. Ford Jr, K. Demouchet, Comparison of hydrogen bonds, halogen bonds, $\mathrm{CH} \cdot \pi$ interactions, and $\mathrm{CX} * \pi$ interactions using high-level ab initio methods, Chem. Phys. Lett. 621 (2015) 165-170.

[10] P.L. Wash, S. Ma, U. Obst, J. Rebek, Nitrogen-halogen intermolecular forces in solution, J. Am. Chem. Soc. 121 (1999) 7973-7974.

[11] O. Donoso-Tauda, P. Jaque, J. Elguero, I. Alkorta, Traditional and Ion-Pair HalogenBonded Complexes Between Chlorine and Bromine Derivatives and a NitrogenHeterocyclic Carbene, J. Phys. Chem. A 118 (2014) 9552-9560.

[12] G. Cavallo, P. Metrangolo, R. Milani, T. Pilati, A. Priimagi, G. Resnati, G. Terraneo, The Halogen Bond, Chem. Rev. 116 (2016) 2478-2601.

[13] I. Alkorta, G. Sanchez-Sanz, J. Elguero, J.E.D. Bene, FCl:PCX complexes: Old and new types of halogen bonds, J. Phys. Chem. A 116 (2012) 2300-2308.

[14] P. Metrangolo, H. Neukirch, T. Pilati, G. Resnati, Halogen bonding based recognition processes: A world parallel to hydrogen bonding, Acc. Chem. Res. 38 (2005) 386-395.

[15] P. Politzer, J.S. Murray, in: S. Scheiner (Ed.), Noncovalent Forces, Springer, Dordrecht, Netherlands, 2015, p. 357-389.

[16] S. Scheiner, Sensitivity of Noncovalent Bonds to Intermolecular Separation: Hydrogen, Halogen, Chalcogen, and Pnicogen Bonds, CrystEngComm 15 (2013) 3119-3124.

[17] E. Danelius, H. Andersson, P. Jarvoll, K. Lood, J. Gräfenstein, M. Erdélyi, Halogen Bonding: A Powerful Tool for Modulation of Peptide Conformation, Biochem. 56 (2017) 3265-3272.

[18] R. Tepper, U.S. Schubert, Halogen Bonding in Solution: Anion Recognition, Templated Self-Assembly, and Organocatalysis, Angew. Chem. Int. Ed. 57 (2018) 6004-6016. 
[19] M. Iwaoka, S. Tomoda, Nature of the intramolecular Se $\cdots$ N nonbonded interaction of 2selenobenzylamine derivatives. An experimental evaluation by ${ }^{1} \mathrm{H},{ }^{77} \mathrm{Se}$, and ${ }^{15} \mathrm{~N} \mathrm{NMR}$ spectroscopy, J. Am. Chem. Soc. 118 (1996) 8077-8084.

[20] G. Sánchez-Sanz, I. Alkorta, J. Elguero, Theoretical study of the HXYH dimers (X, Y = $\mathrm{O}, \mathrm{S}, \mathrm{Se})$. Hydrogen bonding and chalcogen-chalcogen interactions, Mol. Phys. 109 (2011) 2543-2552.

[21] U. Adhikari, S. Scheiner, Sensitivity of pnicogen, chalcogen, halogen and H-bonds to angular distortions, Chem. Phys. Lett. 532 (2012) 31-35.

[22] U. Adhikari, S. Scheiner, Effects of Charge and Substituent on the S $\cdots$ N Chalcogen Bond, J. Phys. Chem. A 118 (2014) 3183-3192.

[23] V.d.P.N. Nziko, S. Scheiner, Chalcogen Bonding between Tetravalent $\mathrm{SF}_{4}$ and Amines, J. Phys. Chem. A 118 (2014) 10849-10856.

[24] R.J. Fick, G.M. Kroner, B. Nepal, R. Magnani, S. Horowitz, R.L. Houtz, S. Scheiner, R.C. Trievel, Sulfur-Oxygen Chalcogen Bonding Mediates AdoMet Recognition in the Lysine Methyltransferase SET7/9, ACS Chem. Biol. 11 (2016) 748-754.

[25] M.D. Esrafili, R. Nurazar, Chalcogen bonds formed through $\pi$-holes: $\mathrm{SO}_{3}$ complexes with nitrogen and phosphorus bases, Mol. Phys. 114 (2016) 276-282.

[26] K.W. Klinkhammer, P. Pyykko, Ab initio interpretation of the closed-shell intermolecular E*-E attraction in dipnicogen $\left(\mathrm{H}_{2} \mathrm{E}-\mathrm{EH}_{2}\right)_{2}$ and $(\mathrm{HE}-\mathrm{EH})_{2}$ hydride model dimers, Inorg. Chem. 34 (1995) 4134-4138.

[27] J. Moilanen, C. Ganesamoorthy, M.S. Balakrishna, H.M. Tuononen, Weak interactions between trivalent pnictogen centers: Computational analysis of bonding in dimers $\mathrm{X}_{3} \mathrm{E}^{\cdots} \mathrm{EX}_{3}$ ( $\mathrm{E}=$ Pnictogen, $\mathrm{X}=$ Halogen), Inorg. Chem. 48 (2009) 6740-6747.

[28] J.E.D. Bene, I. Alkorta, G. Sanchez-Sanz, J. Elguero, Structures, energies, bonding, and NMR properties of pnicogen complexes $\mathrm{H}_{2} \mathrm{XP}: \mathrm{NXH}_{2}\left(\mathrm{X}=\mathrm{H}, \mathrm{CH}_{3}, \mathrm{NH}_{2}, \mathrm{OH}, \mathrm{F}, \mathrm{Cl}\right), \mathrm{J}$. Phys. Chem. A 115 (2011) 13724-13731.

[29] A. Bauzá, D. Quiñonero, P.M. Deyà, A. Frontera, Pnicogen- $\pi$ complexes: theoretical study and biological implications, Phys. Chem. Chem. Phys. 14 (2012) 14061-14066.

[30] Q.-Z. Li, R. Li, X.-F. Liu, W.-Z. Li, J.-B. Cheng, Concerted interaction between pnicogen and halogen bonds in $\mathrm{XCl}-\mathrm{FH}_{2} \mathrm{P}-\mathrm{NH}_{3}(\mathrm{X}=\mathrm{F}, \mathrm{OH}, \mathrm{CN}, \mathrm{NC}$, and $\mathrm{FCC})$, ChemPhysChem. 13 (2012) 1205-1212.

[31] S. Scheiner, The pnicogen bond: Its relation to hydrogen, halogen, and other noncovalent bonds, Acc. Chem. Res. 46 (2013) 280-288.

[32] S. Scheiner, Detailed comparison of the pnicogen bond with chalcogen, halogen and hydrogen bonds, Int. J. Quantum Chem. 113 (2013) 1609-1620.

[33] A. Bauzá, T.J. Mooibroek, A. Frontera, $\sigma$-Hole Opposite to a Lone Pair: Unconventional Pnicogen Bonding Interactions between $\mathrm{ZF}_{3}(\mathrm{Z}=\mathrm{N}, \mathrm{P}, \mathrm{As}$, and $\mathrm{Sb}$ ) Compounds and Several Donors, ChemPhysChem. 17 (2016) 1608-1614.

[34] S. Scheiner, Can two trivalent $\mathrm{N}$ atoms engage in a direct $\mathrm{N} \cdots \mathrm{N}$ noncovalent interaction?, Chem. Phys. Lett. 514 (2011) 32-35.

[35] L. Vogel, P. Wonner, S.M. Huber, Chalcogen Bonding: An Overview, Angew. Chem. Int. Ed. 58 (2019) 1880-1891.

[36] L.-J. Riwar, N. Trapp, K. Root, R. Zenobi, F. Diederich, Supramolecular Capsules: Strong versus Weak Chalcogen Bonding, Angew. Chem. Int. Ed. 57 (2018) 1725917264. 
[37] D. Cesario, M. Fortino, T. Marino, F. Nunzi, N. Russo, E. Sicilia, The role of the halogen bond in iodothyronine deiodinase: Dependence on chalcogen substitution in naphthylbased mimetics, J. Comput. Chem. 40 (2019) 944-951.

[38] M. Virkki, A. Maurice, A. Forni, M. Sironi, V. Dichiarante, P.-F. Brevet, P. Metrangolo, M. Kauranen, A. Priimagi, On the molecular optical nonlinearity of halogen-bondforming azobenzenes, Phys. Chem. Chem. Phys. 20 (2018) 28810-28817.

[39] M.D. Esrafili, M. Vakili, M. Solimannejad, Cooperative effects in pnicogen bonding: $\left(\mathrm{PH}_{2} \mathrm{~F}\right)_{2-7}$ and $\left(\mathrm{PH}_{2} \mathrm{Cl}\right)_{2-7}$ clusters, Chem. Phys. Lett. 609 (2014) 37-41.

[40] U. Adhikari, S. Scheiner, Comparison of $\mathrm{P} \cdots \mathrm{D}(\mathrm{D}=\mathrm{P}, \mathrm{N})$ with other noncovalent bonds in molecular aggregates, J. Chem. Phys. 135 (2011) 184306.

[41] J.E. Del Bene, I. Alkorta, J. Elguero, Hydrogen and Halogen Bonding in Cyclic $\mathrm{FH}_{(4-}$ n): $: \mathrm{Cl}_{\mathrm{n}}$ Complexes, for $\mathrm{n}=0$-4, J. Phys. Chem. A 122 (2018) 2587-2597.

[42] M.D. Esrafili, N.L. Hadipour, Characteristics and nature of halogen bonds in linear clusters of $\mathrm{NCX}(\mathrm{X}=\mathrm{Cl}$, and $\mathrm{Br})$ : an ab initio, NBO and QTAIM study, Mol. Phys. 109 (2011) 2451-2460.

[43] J.M. Guevara-Vela, D. Ochoa-Resendiz, A. Costales, R. Hernández-Lamoneda, Á. Martín Pendás, Halogen Bonds in Clathrate Cages: A Real Space Perspective, ChemPhysChem. 19 (2018) 2512-2517.

[44] J.E. Del Bene, I. Alkorta, J. Elguero, Anionic complexes of $\mathrm{F}^{-}$and $\mathrm{Cl}^{-}$with substituted methanes: Hydrogen, halogen, and tetrel bonds, Chem. Phys. Lett. 655-656 (2016) 115119.

[45] G. Sánchez-Sanz, C. Trujillo, Improvement of Anion Transport Systems by Modulation of Chalcogen Interactions: The influence of solvent, J. Phys. Chem. A 122 (2018) 13691377.

[46] S. Chakraborty, S. Maji, R. Ghosh, R. Jana, A. Datta, P. Ghosh, Aryl-platform-based tetrapodal 2-iodo-imidazolium as an excellent halogen bond receptor in aqueous medium, Chem. Commun. 55 (2019) 1506-1509.

[47] S. Scheiner, Differential Binding of Tetrel-Bonding Bipodal Receptors to Monatomic and Polyatomic Anions, Molecules 24 (2019) 227.

[48] L.M. Lee, M. Tsemperouli, A.I. Poblador-Bahamonde, S. Benz, N. Sakai, K. Sugihara, S. Matile, Anion Transport with Pnictogen Bonds in Direct Comparison with Chalcogen and Halogen Bonds, J. Am. Chem. Soc. 141 (2019) 810-814.

[49] J.Y.C. Lim, I. Marques, V. Félix, P.D. Beer, Chiral halogen and chalcogen bonding receptors for discrimination of stereo- and geometric dicarboxylate isomers in aqueous media, Chem. Commun. 54 (2018) 10851-10854.

[50] S. Scheiner, Comparison of halide receptors based on $\mathrm{H}$, halogen, chalcogen, pnicogen, and tetrel bonds, Faraday Disc. 203 (2017) 213-226.

[51] N.A. Semenov, D.E. Gorbunov, M.V. Shakhova, G.E. Salnikov, I.Y. Bagryanskaya, V.V. Korolev, J. Beckmann, N.P. Gritsan, A.V. Zibarev, Donor-Acceptor Complexes between 1,2,5-Chalcogenadiazoles (Te, Se, S) and the Pseudohalides $\mathrm{CN}-$ and $\mathrm{XCN}-(\mathrm{X}=\mathrm{O}, \mathrm{S}$, Se, Te), Chem. Eur. J. 24 (2018) 12983-12991.

[52] S. Scheiner, Assembly of Effective Halide Receptors from Components. Comparing Hydrogen, Halogen, and Tetrel Bonds, J. Phys. Chem. A 121 (2017) 3606-3615.

[53] J.Y.C. Lim, P.D. Beer, A pyrrole-containing cleft-type halogen bonding receptor for oxoanion recognition and sensing in aqueous solvent media, New J. Chem. 42 (2018) 10472-10475. 
[54] J. Stoesser, G. Rojas, D. Bulfield, P.I. Hidalgo, J. Pasan, C. Ruiz-Perez, C.A. Jimenez, S.M. Huber, Halogen bonding two-point recognition with terphenyl derivatives, New J. Chem. 42 (2018) 10476-10480.

[55] A. Dreger, E. Engelage, B. Mallick, P.D. Beer, S.M. Huber, The role of charge in 1,2,3triazol(ium)-based halogen bonding activators, Chem. Commun. 54 (2018) 4013-4016.

[56] L. Zhou, Y. Lu, Z. Xu, C. Peng, H. Liu, Ion-pair recognition based on halogen bonding: a case of the crown-ether receptor with iodo-trizole moiety, Struct. Chem. 29 (2018) 533540.

[57] S. Scheiner, Tetrel Bonding as a Vehicle for Strong and Selective Anion Binding, Molecules 23 (2018) 1147-1155.

[58] Y. Zhao, D.G. Truhlar, The M06 suite of density functionals for main group thermochemistry, thermochemical kinetics, noncovalent interactions, excited states, and transition elements: two new functionals and systematic testing of four M06-class functionals and 12 other functionals, Theor. Chem. Acc. 120 (2008) 215-241.

[59] T.H.J. Dunning, Gaussian basis sets for use in correlated molecular calculations. I. The atoms boron through neon and hydrogen, J. Chem. Phys. 90 (1989) 1007-1023.

[60] A.P. Orlova, P.G. Jasien, Halogen bonding in self-assembling systems: A comparison of intra- and interchain binding energies, Comput. Theor. Chem. 1139 (2018) 63-69.

[61] A. Forni, S. Pieraccini, D. Franchini, M. Sironi, Assessment of DFT Functionals for QTAIM Topological Analysis of Halogen Bonds with Benzene, J. Phys. Chem. A 120 (2016) 9071-9080.

[62] A. Bauzá, X. García-Llinás, A. Frontera, Charge-assisted triel bonding interactions in solid state chemistry: A combined computational and crystallographic study, Chem. Phys. Lett. 666 (2016) 73-78.

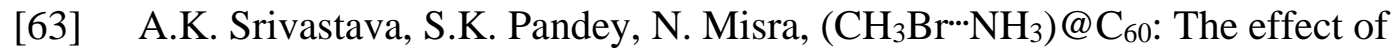
nanoconfinement on halogen bonding, Chem. Phys. Lett. 662 (2016) 240-243.

[64] S. Scheiner, Dependence of NMR chemical shifts upon CH bond lengths of a methyl group involved in a tetrel bond, Chem. Phys. Lett. 714 (2019) 61-64.

[65] M.D. Esrafili, E. Vessally, A theoretical evidence for cooperative enhancement in aerogen-bonding interactions: Open-chain clusters of $\mathrm{KrOF}_{2}$ and $\mathrm{XeOF}_{2}$, Chem. Phys. Lett. 662 (2016) 80-85.

[66] N. Mardirossian, M. Head-Gordon, How Accurate Are the Minnesota Density Functionals for Noncovalent Interactions, Isomerization Energies, Thermochemistry, and Barrier Heights Involving Molecules Composed of Main-Group Elements?, J. Chem. Theory Comput. 12 (2016) 4303-4325.

[67] Z. Chi, W. Dong, Q. Li, X. Yang, S. Scheiner, S. Liu, Carbene triel bonds between TrR 3 $(\operatorname{Tr}=\mathrm{B}, \mathrm{Al})$ and N-heterocyclic carbenes, Int. J. Quantum Chem. 119 (2019) e25867.

[68] M. Saberinasab, S. Salehzadeh, M. Solimannejad, The effect of a strong cation" $\pi$ interaction on a weak selenium $\cdots \pi$ interaction: A theoretical study, Comput. Theor. Chem. 1092 (2016) 41-46.

[69] Y. Wang, Y. Zeng, X. Li, L. Meng, X. Zhang, The mutual influence between $\pi$-hole pnicogen bonds and $\sigma$-hole halogen bonds in complexes of $\mathrm{PO}_{2} \mathrm{Cl}$ and $\mathrm{XCN} / \mathrm{C}_{6} \mathrm{H}_{6}(\mathrm{X}=\mathrm{F}$, Cl, Br), Struct. Chem. 27 (2016) 1427-1437.

[70] L. Spada, Q. Gou, Y. Geboes, W.A. Herrebout, S. Melandri, W. Caminati, Rotational Study of Dimethyl Ether-Chlorotrifluoroethylene: Lone Pair $\cdots \pi$ Interaction Links the Two Subunits, J. Phys. Chem. A 120 (2016) 4939-4943. 
[71] M. Michalczyk, W. Zierkiewicz, S. Scheiner, Triel-Bonded Complexes between $\operatorname{TrR}_{3}$ ( $\mathrm{Tr}=\mathrm{B}, \mathrm{Al}, \mathrm{Ga} ; \mathrm{R}=\mathrm{H}, \mathrm{F}, \mathrm{Cl}, \mathrm{Br}, \mathrm{CH}_{3}$ ) and Pyrazine, ChemPhysChem. 19 (2018) 31223133.

[72] R. Shukla, D. Chopra, "Pnicogen bonds" or "chalcogen bonds": exploiting the effect of substitution on the formation of P.'Se noncovalent bonds, Phys. Chem. Chem. Phys. 18 (2016) 13820-13829.

[73] S. Scheiner, Ability of IR and NMR Spectral Data to Distinguish between a Tetrel Bond and a Hydrogen Bond, J. Phys. Chem. A 122 (2018) 7852-7862.

[74] Q. Tang, Q. Li, Non-additivity of F substituent in enhancing the halogen bond in $\mathrm{C}_{6} \mathrm{H}_{5} \mathrm{I} \cdots \mathrm{NCH}$, Comput. Theor. Chem. 1070 (2015) 21-26.

[75] W. Li, Y. Zeng, X. Li, Z. Sun, L. Meng, The competition of $Y \cdots O$ and $X \cdots N$ halogen bonds to enhance the group $\mathrm{V} \sigma$-hole interaction in the $\mathrm{NCY} \cdots \mathrm{O}=\mathrm{PH}_{3} \cdot \mathrm{NCX}$ and $\mathrm{O}=\mathrm{PH}_{3} \cdots{ }^{\cdots} \mathrm{NCX} \cdots \mathrm{NCY}$ (X, Y=F, Cl, and $\mathrm{Br}$ ) complexes, J. Comput. Chem. 36 (2015) 13491358.

[76] Y. Geboes, F.D. Proft, W.A. Herrebout, Expanding Lone Pair $\cdots \pi$ Interactions to Nonaromatic Systems and Nitrogen Bases: Complexes of $\mathrm{C}_{2} \mathrm{~F}_{3} \mathrm{X}(\mathrm{X}=\mathrm{F}, \mathrm{Cl}, \mathrm{Br}, \mathrm{I})$ and TMA-d9, J. Phys. Chem. A 119 (2015) 5597-5606.

[77] S.F. Boys, F. Bernardi, The calculation of small molecular interactions by the differences of separate total energies. Some procedures with reduced errors, Mol. Phys. 19 (1970) 553-566.

[78] M.J. Frisch, G.W. Trucks, H.B. Schlegel, G.E. Scuseria, M.A. Robb, J.R. Cheeseman, G. Scalmani, V. Barone, B. Mennucci, G.A. Petersson, H. Nakatsuji, M. Caricato, X. Li, H.P. Hratchian, A.F. Izmaylov, J. Bloino, G. Zheng, J.L. Sonnenberg, M. Hada, M. Ehara, K. Toyota, R. Fukuda, J. Hasegawa, M. Ishida, T. Nakajima, Y. Honda, O. Kitao, H. Nakai, T. Vreven, J. Montgomery, J. A., J.E. Peralta, F. Ogliaro, M. Bearpark, J.J. Heyd, E. Brothers, K.N. Kudin, V.N. Staroverov, R. Kobayashi, J. Normand, K. Raghavachari, A. Rendell, J.C. Burant, S.S. Iyengar, J. Tomasi, M. Cossi, N. Rega, J.M. Millam, M. Klene, J.E. Knox, J.B. Cross, V. Bakken, C. Adamo, J. Jaramillo, R. Gomperts, R.E. Stratmann, O. Yazyev, A.J. Austin, R. Cammi, C. Pomelli, J.W. Ochterski, R.L. Martin, K. Morokuma, V.G. Zakrzewski, G.A. Voth, P. Salvador, J.J. Dannenberg, S. Dapprich, A.D. Daniels, O. Farkas, J.B. Foresman, J.V. Ortiz, J. Cioslowski, D.J. Fox, Gaussian 09, Wallingford, CT, 2009.

[79] F.A. Bulat, A. Toro-Labbé, T. Brinck, J.S. Murray, P. Politzer, Quantitative analysis of molecular surfaces: areas, volumes, electrostatic potentials and average local ionization energies, J. Mol. Model. 16 (2010) 1679-1691.

[80] T.A. Keith, AIMALL. TK Gristmill Software, Overland Park KS, 2013.

[81] A.E. Reed, F. Weinhold, Natural bond orbital analysis of near Hartree-Fock water dimer, J. Chem. Phys. 78 (1983) 4066-4073.

[82] A.E. Reed, L.A. Curtiss, F. Weinhold, Natural population analysis, J. Chem. Phys. 83 (1985) 735-746.

[83] F. Weinhold, Natural bond orbital analysis: A critical overview of relationships to alternative bonding perspectives, J. Comput. Chem. 33 (2012) 2363-2379.

[84] G.E. Garrett, G.L. Gibson, R.N. Straus, D.S. Seferos, M.S. Taylor, Chalcogen Bonding in Solution: Interactions of Benzotelluradiazoles with Anionic and Uncharged Lewis Bases, J. Am. Chem. Soc. 137 (2015) 4126-4133. 
[85] M.W.D. Hanson-Heine, N.A. Besley, Spectroscopic and structural analysis of mixed carbon dioxide and fluorinated methane clusters, Chem. Phys. Lett. 638 (2015) 191-195.

[86] R.D. Parra, Metal-ion binding by cyclic halogen-bonded structures: A theoretical study using $\mathrm{M}-(\mathrm{BrZ})_{4}$ clusters $\left(\mathrm{Z}=\mathrm{F}\right.$ or $\mathrm{NH}_{2} ; \mathrm{M}=\mathrm{Li}^{+}, \mathrm{Na}^{+}$, or $\left.\mathrm{Mg}^{2+}\right)$, Chem. Phys. Lett. 637 (2015) 177-181.

[87] S.J. Grabowski, Clusters of Ammonium Cation-Hydrogen Bond versus $\sigma$-Hole Bond, ChemPhysChem. 15 (2014) 876-884.

[88] I. Alkorta, A. Legon, An Ab Initio Investigation of the Geometries and Binding Strengths of Tetrel-, Pnictogen-, and Chalcogen-Bonded Complexes of $\mathrm{CO}_{2}, \mathrm{~N}_{2} \mathrm{O}$, and $\mathrm{CS}_{2}$ with Simple Lewis Bases: Some Generalizations, Molecules 23 (2018) 2250.

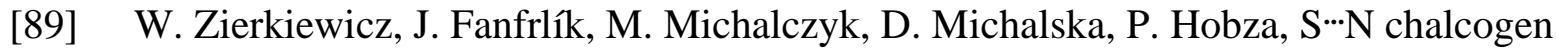
bonded complexes of carbon disulfide with diazines. Theoretical study, Chem. Phys. 500 (2018) 37-44.

[90] Y. Xu, J. Huang, B. Gabidullin, D.L. Bryce, A rare example of a phosphine as a halogen bond acceptor, Chem. Commun. 54 (2018) 11041-11043.

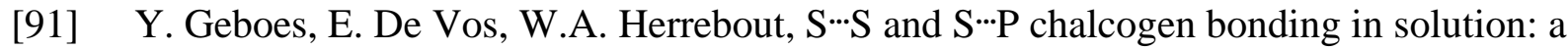
cryospectroscopic study of the complexes of 2,2,4,4-tetrafluoro-1,3-dithietane with dimethyl sulfide and trimethylphosphine, New J. Chem. 42 (2018) 10563-10571.

[92] P.K. Sruthi, N. Ramanathan, S. Sarkar, K. Sundararajan, Pentavalent phosphorus as a unique phosphorus donor in $\mathrm{POCl}_{3}$ homodimer and $\mathrm{POCl}_{3}-\mathrm{H}_{2} \mathrm{O}$ heterodimer: matrix isolation infrared spectroscopic and computational studies, Phys. Chem. Chem. Phys. 20 (2018) 22058-22075. 
Table 1. Total interaction energies $\left(-\mathrm{E}_{\text {int }}\right)$ for $\mathrm{Cl}^{-}(\mathrm{solv})_{4}$ complexes, and energy required $\left(\mathrm{E}_{\text {tet }}\right)$ to distort into pure tetrahedral structure, all in $\mathrm{kcal} / \mathrm{mol}$.

\begin{tabular}{|l|l|l|l|}
\hline solv & \multicolumn{1}{|c|}{$-\mathrm{E}_{\text {int }}$} & \multicolumn{1}{|c|}{$\mathrm{E}_{\text {tet }}$} & \multicolumn{1}{c|}{$-\mathrm{E}_{\text {int }}(\mathrm{MP} 2)^{\mathrm{a}}$} \\
\hline $\mathrm{HCl}$ & 65.96 & - & 63.82 \\
\hline $\mathrm{HF}$ & 74.49 & - & 69.46 \\
\hline $\mathrm{BrF}$ & 92.59 & 0.23 & 83.14 \\
\hline $\mathrm{ClF}$ & 75.13 & 0.04 & 66.77 \\
\hline $\mathrm{ClCN}$ & 56.01 & 0.36 & 51.11 \\
\hline $\mathrm{SF}_{2}$ & 69.96 & 4.67 & 58.97 \\
\hline $\mathrm{SeF}_{2}$ & 89.88 & 7.88 & 80.82 \\
\hline $\mathrm{SeFMe}$ & 75.41 & 2.15 & 69.39 \\
\hline $\mathrm{SeCSe}$ & 47.33 & 1.82 & 42.76 \\
\hline $\mathrm{PF}_{3}$ & 59.09 & 2.35 & 48.69 \\
\hline $\mathrm{AsF}$ & 77.78 & 2.74 & 69.14 \\
\hline $\mathrm{AsCF}$ & 38.00 & 3.68 & 31.24 \\
\hline
\end{tabular}

a using aug-cc-pVDZ basis set, applied to M06-2X geometries

Table 2. QTAIM values of density at bond critical points (au) for $\mathrm{Cl}^{-}(\mathrm{solv})_{4}$ complexes.

\begin{tabular}{|l|l|l|}
\hline solv & \multicolumn{1}{|c|}{ primary $^{\mathrm{a}}$} & \multicolumn{1}{|c|}{ secondary $^{\mathrm{b}}$} \\
\hline $\mathrm{HCl}$ & 0.035 & - \\
\hline $\mathrm{HF}$ & 0.030 & - \\
\hline $\mathrm{BrF}$ & 0.032 & - \\
\hline $\mathrm{ClF}$ & 0.031 & - \\
\hline $\mathrm{ClCN}$ & 0.016 & - \\
\hline $\mathrm{SF}_{2}$ & $0.026-0.040$ & $\begin{array}{l}2 \mathrm{~S} \cdot \cdot \mathrm{S} 0.010-0.039 \\
1 \mathrm{Cl} \cdot \cdot \mathrm{F} 0.010\end{array}$ \\
\hline $\mathrm{SeF}_{2}$ & $0.020-0.032$ & $\begin{array}{l}2 \mathrm{Se} \cdot \cdot \mathrm{Se} 0.013 \\
1 \mathrm{Se} \cdot \cdot \mathrm{F} 0.014\end{array}$ \\
\hline $\mathrm{SeFMe}$ & $0.019-0.025$ & $\begin{array}{l}2 \mathrm{Cl} \cdot \cdot \mathrm{H} 0.010 \\
2 \mathrm{H} \cdot \cdot \mathrm{Se} 0.008\end{array}$ \\
\hline $\mathrm{SeCSe}$ & 0.015 & $4 \mathrm{Se} \cdot \cdot \mathrm{Se} 0.005$ \\
\hline $\mathrm{PF}_{3}$ & $0.021-0.024$ & $\begin{array}{l}3 \mathrm{~F} \cdot \cdot \mathrm{P} 0.006 \\
2 \mathrm{~F} \cdot \cdot \mathrm{F} 0.006\end{array}$ \\
\hline $\mathrm{AsF}$ & & $\begin{array}{l}4 \mathrm{~F} \cdot \cdot \mathrm{As} 0.009 \\
1 \mathrm{~F} \cdot \cdot \mathrm{F} 0.011\end{array}$ \\
\hline $\mathrm{AsCF}$ & $0.019-0.027$ & $\begin{array}{l}3 \mathrm{As} \cdot \cdot \mathrm{As} 0.006 \\
1 \mathrm{As} \cdot \cdot \mathrm{C} 0.006\end{array}$ \\
\hline
\end{tabular}

${ }^{a}$ between $\mathrm{Cl}$ and nearest atom of solvent molecule

between indicated atoms of solvent molecules 
Table 3. NBO values of $\mathrm{E}(2)$ between solvent molecules for $\mathrm{Cl}^{-}(\mathrm{solv})_{4}$ complexes

\begin{tabular}{|c|c|}
\hline solv & $\mathrm{E}(2), \mathrm{kcal} / \mathrm{mol}$ \\
\hline $\mathrm{HCl}$ & none \\
\hline $\mathrm{HF}$ & none \\
\hline $\mathrm{BrF}$ & none \\
\hline $\mathrm{ClF}$ & none \\
\hline $\mathrm{ClCN}$ & none \\
\hline $\mathrm{SF}_{2}$ & 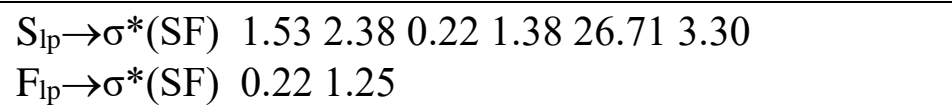 \\
\hline $\mathrm{SeF}_{2}$ & 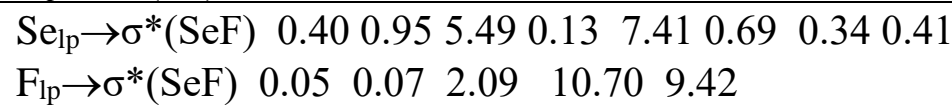 \\
\hline SeFMe & $\begin{array}{lllll}\mathrm{Se}_{\mathrm{lp}} \rightarrow \sigma^{*}(\mathrm{CH}) & 1.77 & 2.61 & 1.23 & 0.46 \\
\mathrm{Se}_{\mathrm{e}} \rightarrow \sigma^{*}(\mathrm{SeC}) & 0.46 & 0.66 & & \\
\mathrm{Se}_{\mathrm{lp} \rightarrow \sigma^{*}(\mathrm{SeF})} & 0.25 & 0.30 & & \end{array}$ \\
\hline SeCSe & $\sigma(\mathrm{SeC}) \rightarrow \sigma^{*}(\mathrm{SeC}) \quad 0.31 \quad 0.18 \quad 0.20 \quad 0.20 \quad 0.22$ \\
\hline $\mathrm{PF}_{3}$ & $\begin{array}{llll}\mathrm{P}_{\mathrm{lp}} \rightarrow \sigma^{*}(\mathrm{PF}) & 0.30 & 0.53 & 0.45 \\
\mathrm{~F}_{\mathrm{lp}} \rightarrow \sigma^{*}(\mathrm{PF}) & 0.72 & 0.26\end{array}$ \\
\hline $\mathrm{AsF}_{3}$ & 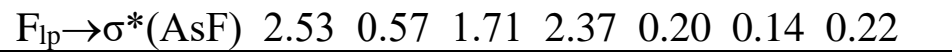 \\
\hline $\mathrm{AsCF}$ & $\begin{array}{lllllll}\sigma(\mathrm{AsC}) \rightarrow \sigma^{*}(\mathrm{AsC}) & 1.58 & 1.38 & 1.38 & 0.21 & 0.46 \\
A s_{\mid \mathfrak{p}} \rightarrow \sigma^{*}(\mathrm{AsC} C & 0.38 & 0.26 & 0.12 & 0.86 & 0.17 & 0.96\end{array}$ \\
\hline
\end{tabular}

Table 4. Total interaction energies (-E $\left.\mathrm{E}_{\text {int }}\right)$ for $\mathrm{Na}^{+}(\mathrm{solv})_{4}$ complexes $(\mathrm{kcal} / \mathrm{mol})$.

\begin{tabular}{|c|c|}
\hline solv & $-E_{\text {int }}$ \\
\hline $\mathrm{HF}$ & 59.81 \\
\hline $\mathrm{H}_{2} \mathrm{O}$ & 77.78 \\
\hline $\mathrm{FBr}$ & 44.68 \\
\hline $\mathrm{FCl}$ & 34.29 \\
\hline $\mathrm{SF}_{2}$ & 49.43 \\
\hline $\mathrm{SeF}_{2}$ & 64.74 \\
\hline $\mathrm{PF}_{3}$ & 52.92 \\
\hline $\mathrm{AsF}_{3}$ & 69.38 \\
\hline
\end{tabular}


Table 5. Molecular electrostatic potential (MEP) extrema ( $\mathrm{kcal} / \mathrm{mol}$ ) on the 0.001 au isodensity surface for isolated molecules.

\begin{tabular}{|c|c|c|}
\hline & $\mathrm{V}_{\mathrm{s}, \max }$ & $\mathrm{V}_{\mathrm{s}, \text { min }}$ \\
\hline $\mathrm{HF}$ & 68.2 & -21.2 \\
\hline $\mathrm{H}_{2} \mathrm{O}$ & 43.3 & -33.3 \\
\hline $\mathrm{FBr}$ & 47.0 & -11.8 \\
\hline $\mathrm{FCl}$ & 38.2 & -8.5 \\
\hline $\mathrm{SF}_{2}$ & 38.5 & -9.8 \\
\hline $\mathrm{SeF}_{2}$ & 48.8 & -14.7 \\
\hline $\mathrm{PF}_{3}$ & 35.0 & -10.7 \\
\hline $\mathrm{AsF}_{3}$ & 44.9 & -16.5 \\
\hline
\end{tabular}



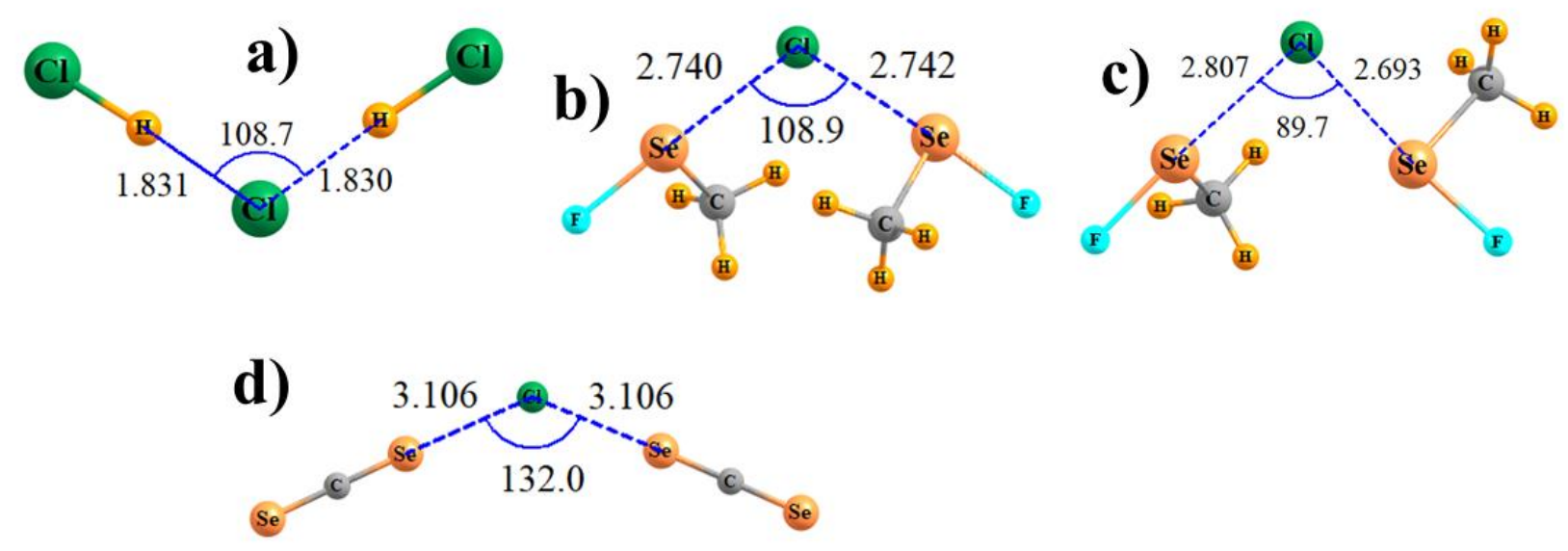

Fig 1. Optimized geometries of $\mathrm{Cl}^{-}$surrounded by two a) $\mathrm{HCl}$ b) and c) SeFMe, and d) SeCSe molecules. Distances in $\AA$, angles in degs.
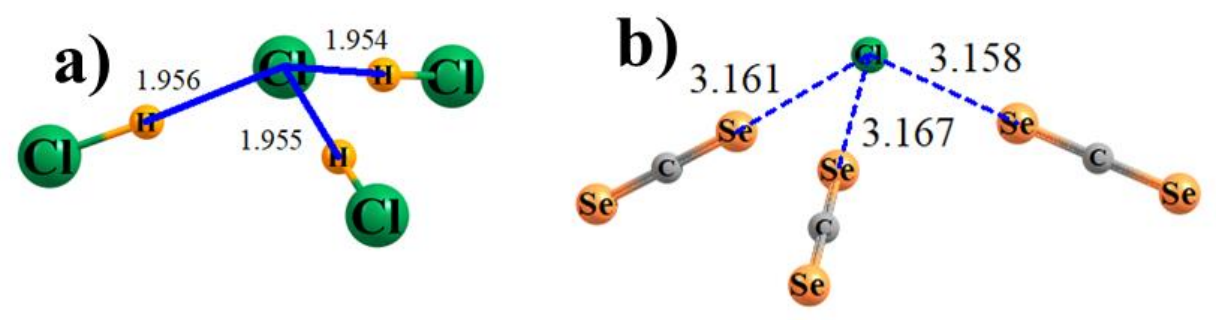

Fig 2. Optimized geometries of $\mathrm{Cl}^{-}$surrounded by three a) $\mathrm{HCl}$ and b) SeCSe molecules. Distances in $\AA$. 

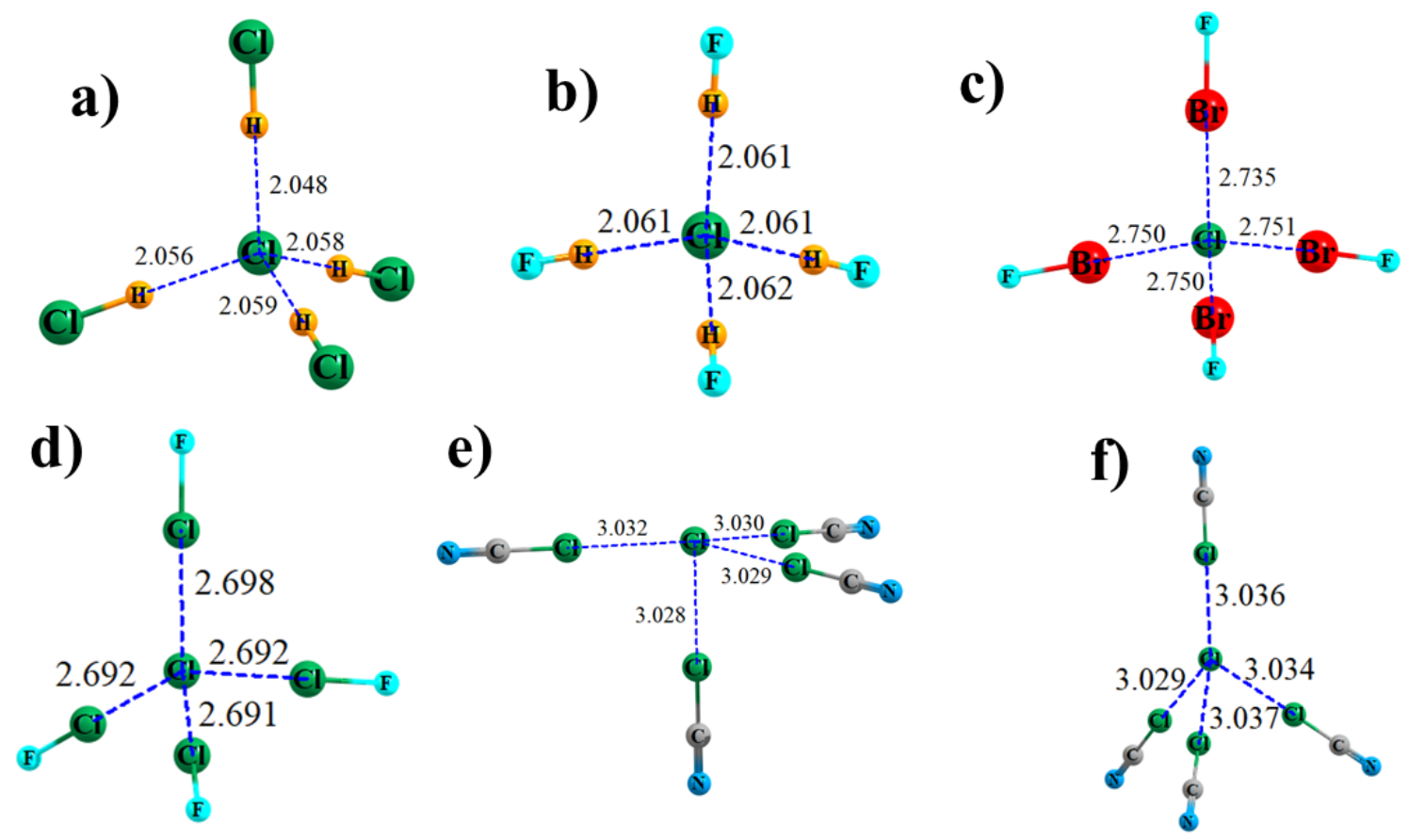

Fig 3. Optimized geometries of $\mathrm{Cl}^{-}$surrounded by four a) $\mathrm{HCl}, \mathrm{b}$ ) $\mathrm{HF}$, c) $\mathrm{BrF}$, d) $\mathrm{ClF}$, e) and f) ClCN molecules. Distances in $\AA$.
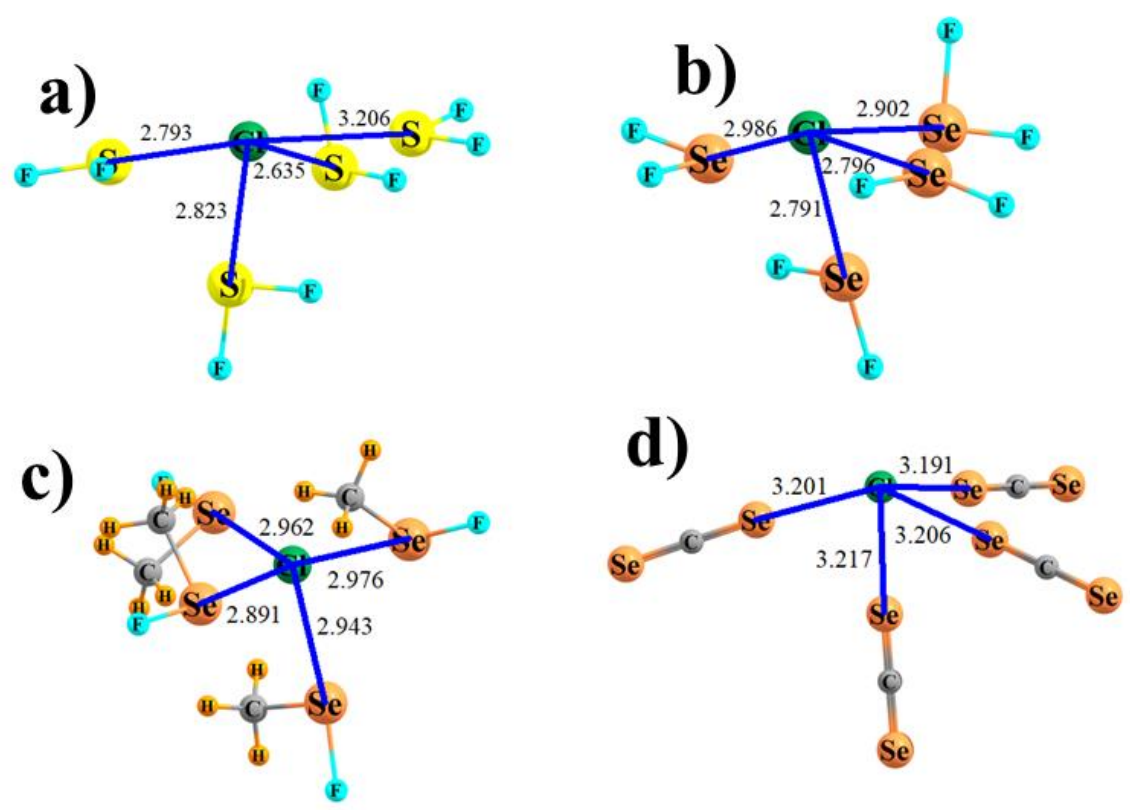

Fig 4. Optimized geometries of $\mathrm{Cl}^{-}$surrounded by four a) $\mathrm{SF}_{2}$, a) $\mathrm{SeF}_{2}$, c) FSeMe, d) $\mathrm{SeCSe}$ molecules. Distances in $\AA$. 

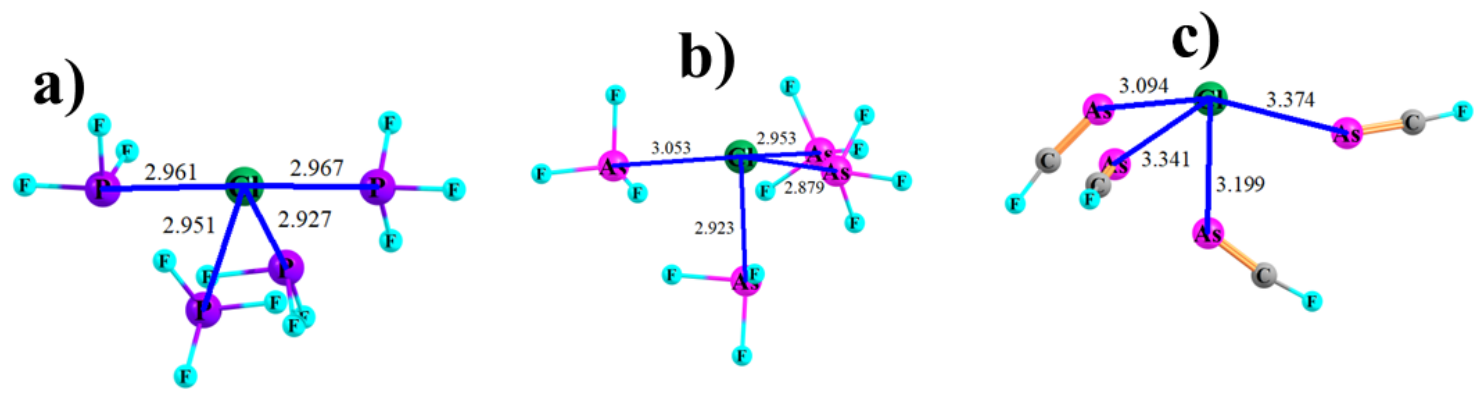

Fig 5. Optimized geometries of $\mathrm{Cl}^{-}$surrounded by four a) $\mathrm{PF}_{3}$, a) $\mathrm{AsF}_{3}$, c)AsCF molecules. Distances in $\AA$.
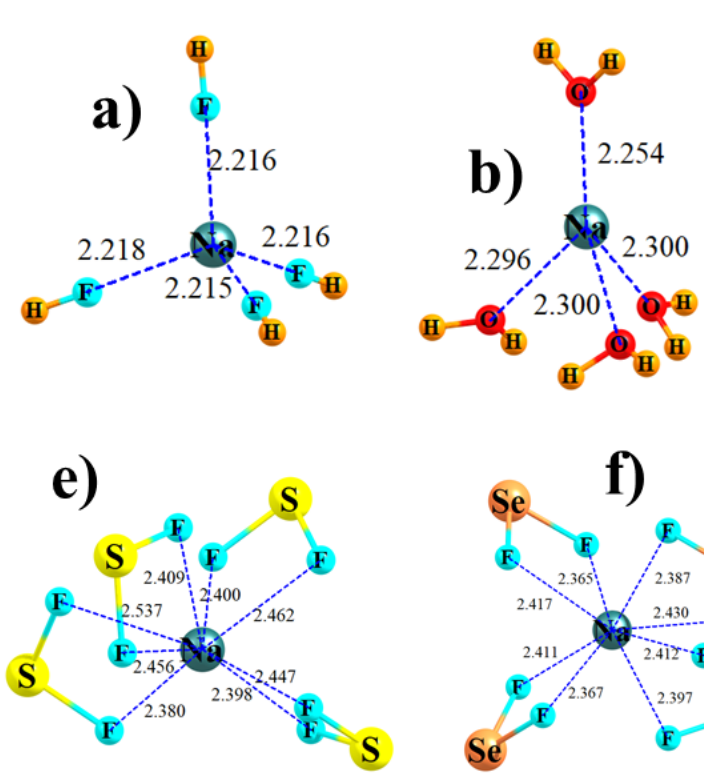
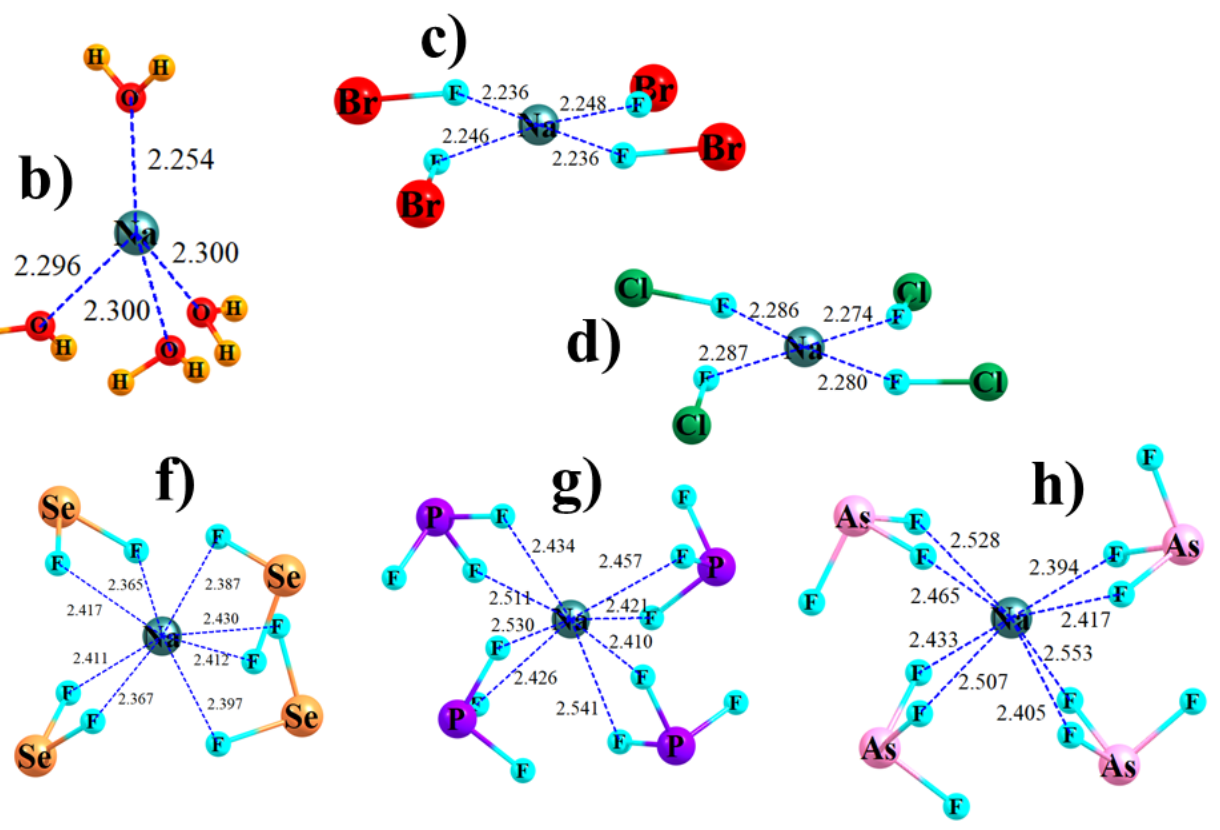

Fig 6. Optimized geometries of $\mathrm{Na}^{+}$surrounded by four solvent molecules. Distances in $\AA$. 

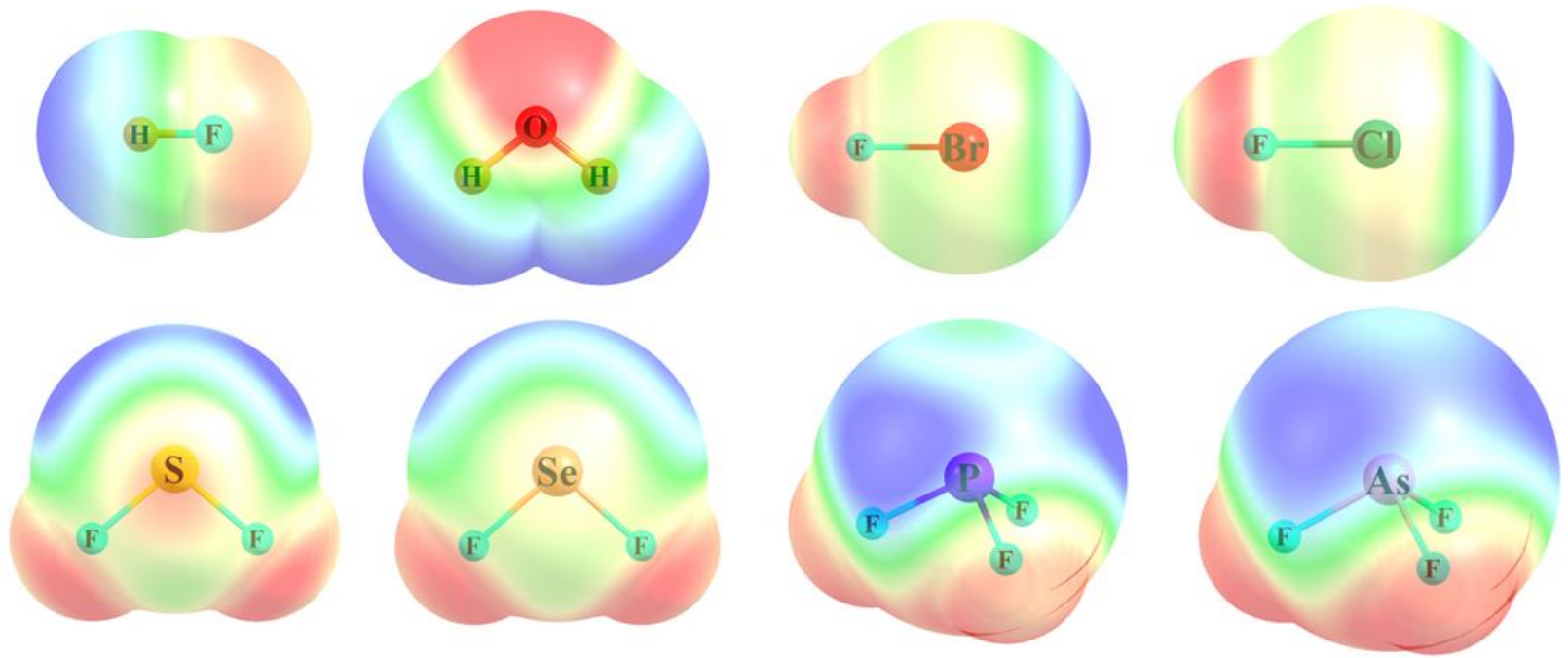

Fig 7. Molecular electrostatic potentials surrounding solvent molecules, on surface corresponding to $1.5 \mathrm{x}$ vdW radii. Blue and red regions indicate most positive and negative potentials, respectively. 